
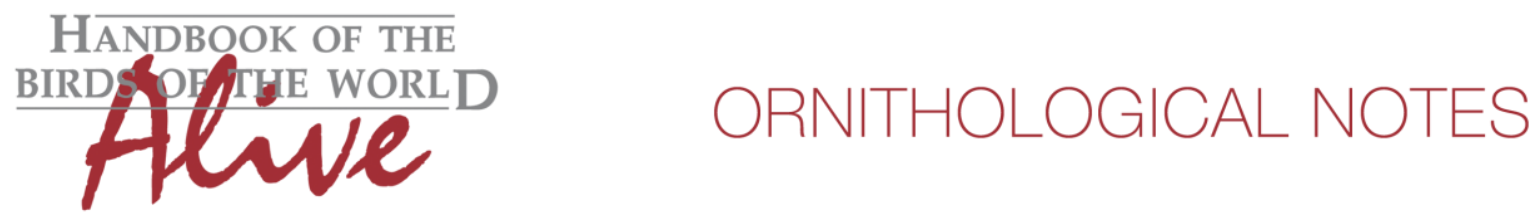

\title{
Notes on the vocalizations of Long-tailed Tit (Aegithalos caudatus)
}

Peter Boesman

In the following we briefly analyze and compare voice of the different races of Long-tailed Tit (Aegithalos caudatus). We also try to quantify the extent of any vocal differences using the criteria proposed by Tobias et al. (2010), as a support for taxonomic review. We have made use of sound recordings available on-line from Xeno Canto (XC).

The two commonest vocalization types are a short series of high-pitched notes and a short descending rattle, which seem to be uttered by all races. Even more, it would seem that there is hardly any difference in basic sound parameters for these two calls over the vast range of this species, as can be appreciated in the following sonograms:

"nominate group" in N Europe and Asia

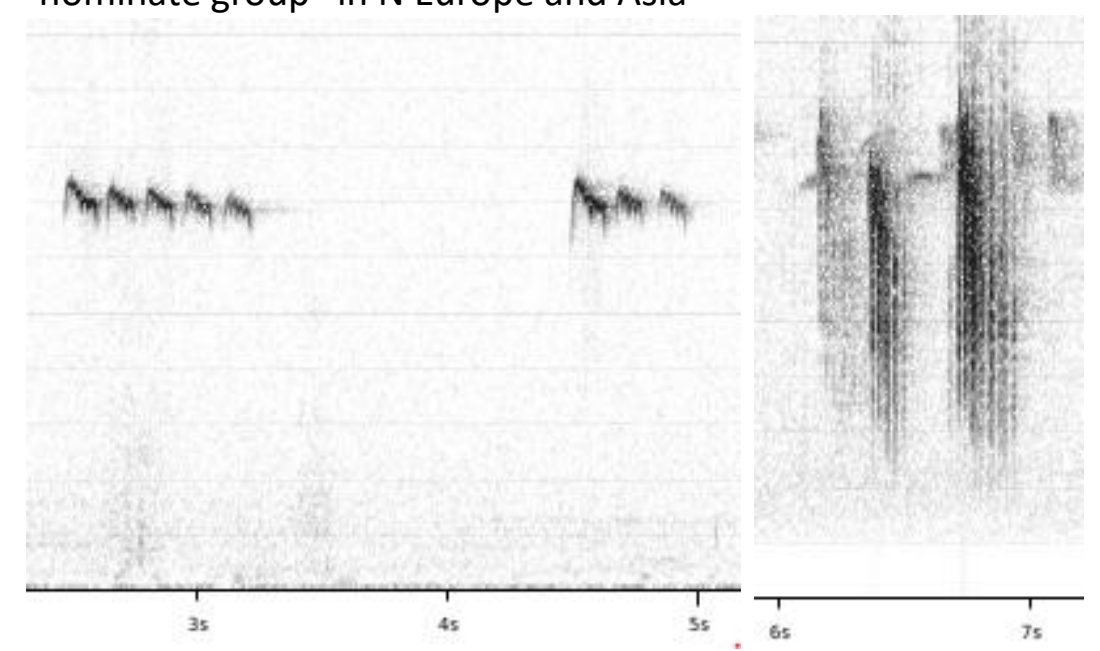

"europaeus group" (including also rosaceus, aremoricus, taiti, macedonicus, tauricus) in S \& W Europe

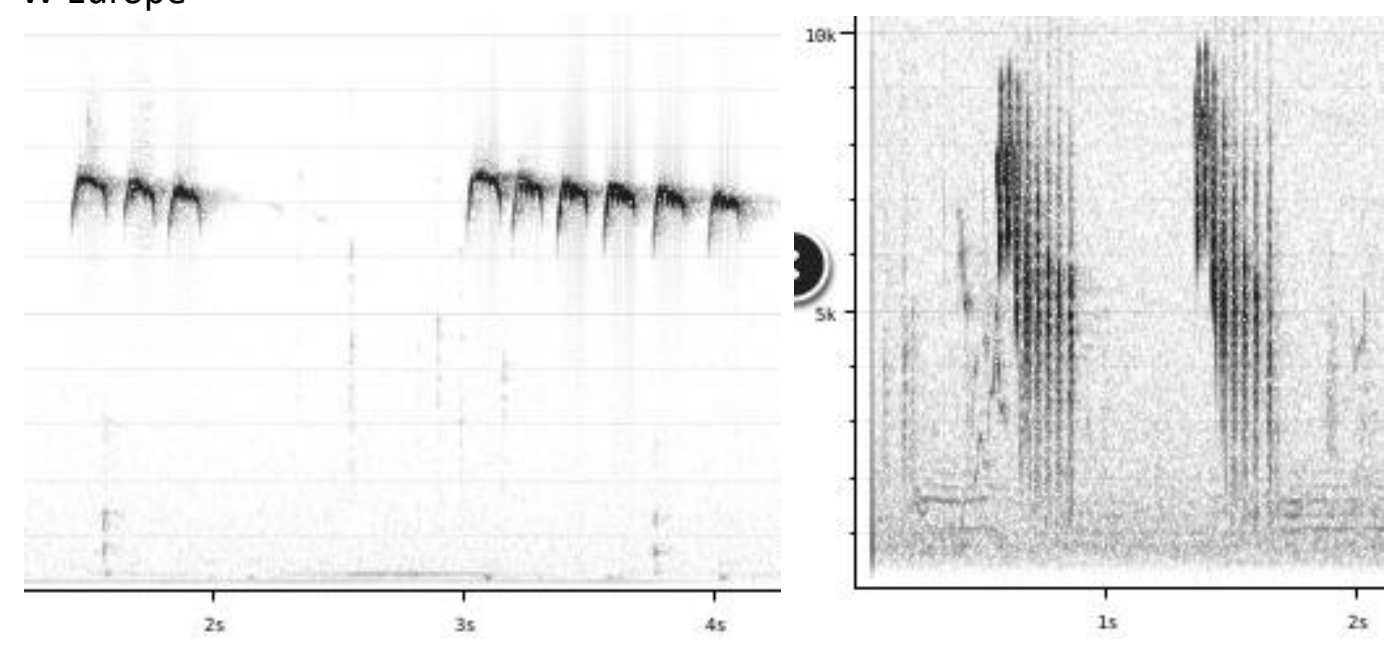



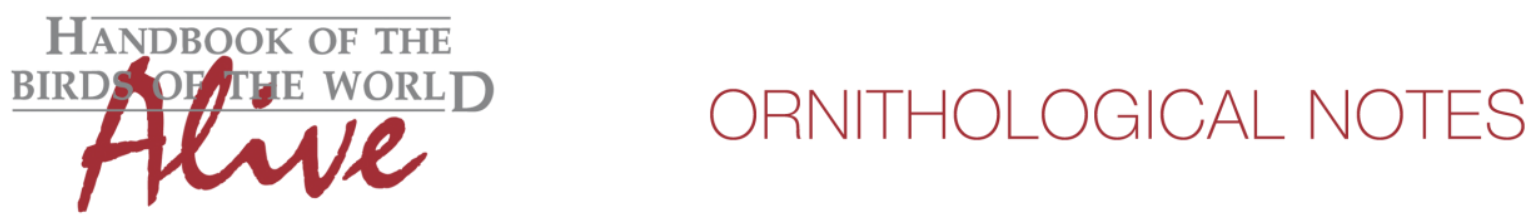

"alpinus group" (including also irbii, italiae, siculus, tephronotus, major, passekii) in Mediterranean Europe and SW Asia

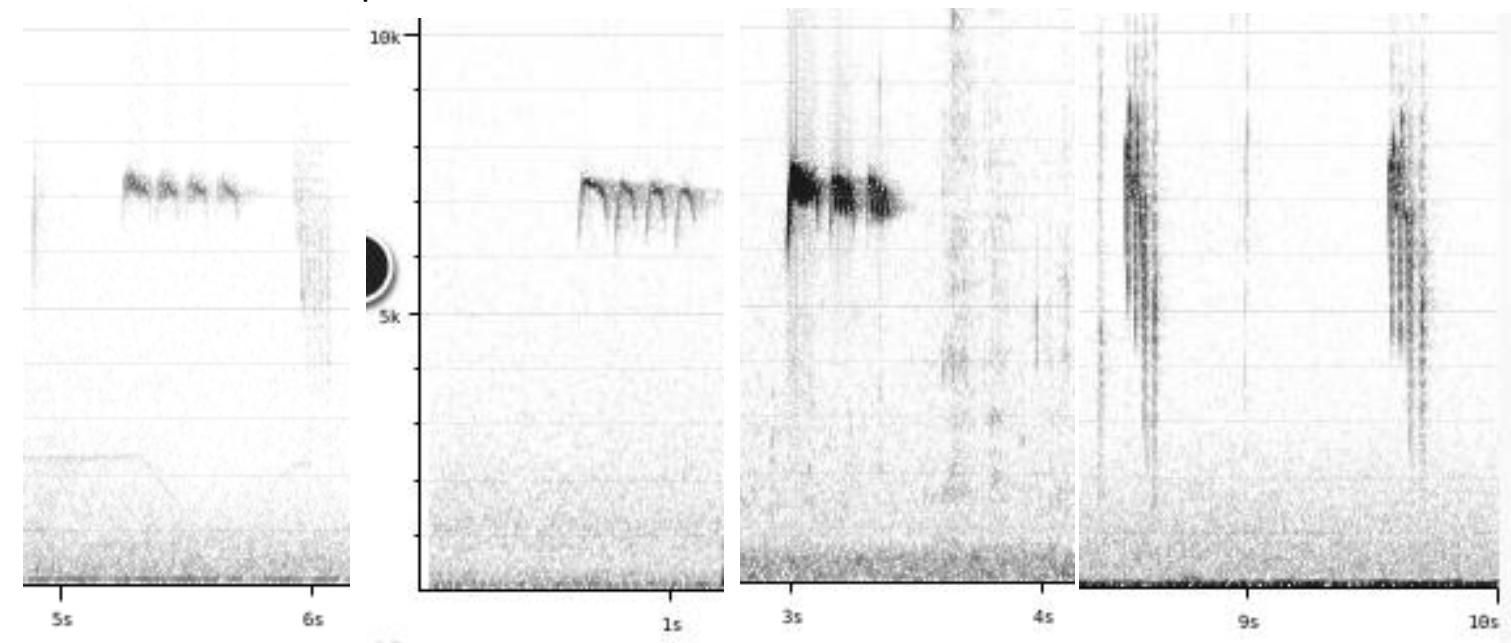

"trivirgatus group" (incorporating kiusiuensis, magnus) in S Korea and Japan

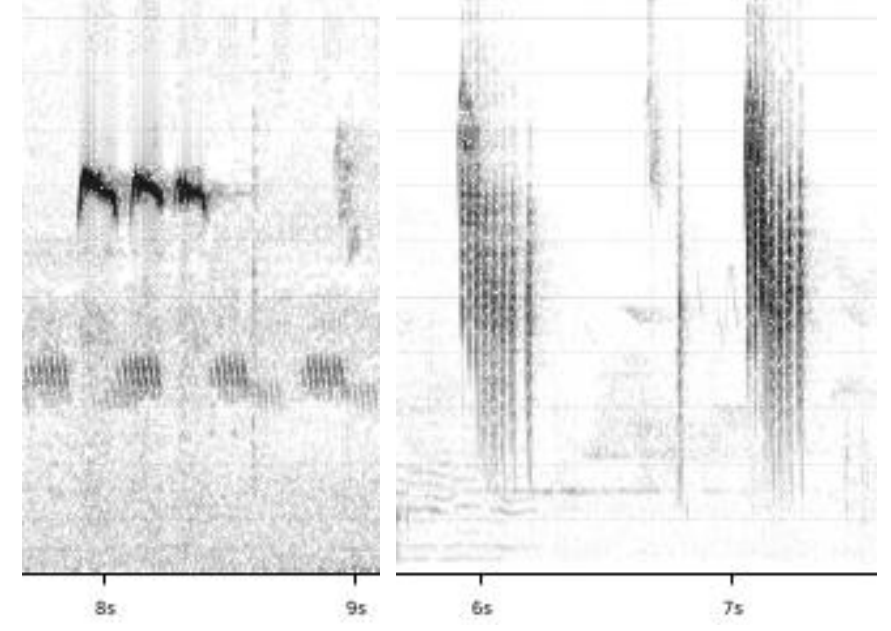

From the above examples it is clear that the two main vocalizations are about identical among these four groups, up to a striking similarity in note shape, which is quite remarkable for a species with multiple races and a vast range!

This note was finalized on 5th March 2016, using sound recordings available on-line at that moment. We would like to thank in particular the many sound recordists who placed their recordings for this species on XC.

\section{References}

Tobias, J.A., Seddon, N., Spottiswoode, C.N., Pilgrim, J.D., Fishpool, L.D.C. \& Collar, N.J. (2010). Quantitative criteria for species delimitation. Ibis 152(4): 724-746. 


\section{Recommended citation}

Boesman, P. (2016). Notes on the vocalizations of Long-tailed Tit (Aegithalos caudatus). HBW Alive Ornithological Note 259. In: Handbook of the Birds of the World Alive. Lynx Edicions, Barcelona. (retrieved from http://www.hbw.com/node/1251587 on 4 October 2016). 